\title{
Survey Methods in Multinational, Multiregional, and Multicultural Contexts Book Review
}

Sokhi Huda, Clarissa Aisyah Putri

To Link this Article: http://dx.doi.org/10.6007/IJARBSS/v11-i3/8922

DOI:10.6007/IJARBSS/v11-i3/8922

Received: 06 January 2021, Revised: 30 January 2021, Accepted: 18 February 2021

Published Online: 06 March 2021

In-Text Citation: (Huda \& Putri, 2021)

To Cite this Article: Huda, S., \& Putri, C. A. (2021). Survey Methods in Multinational, Multiregional, and Multicultural Contexts Book Review. International Journal of Academic Research in Business and Social Sciences, 11(3), 146-153.

Copyright: (c) 2021 The Author(s)

Published by Human Resource Management Academic Research Society (www.hrmars.com) This article is published under the Creative Commons Attribution (CC BY 4.0) license. Anyone may reproduce, distribute, translate and create derivative works of this article (for both commercial and non-commercial purposes), subject to full attribution to the original publication and authors. The full terms of this license may be seen

at: http://creativecommons.org/licences/by/4.0/legalcode

Vol. 11, No. 3, 2021, Pg. 146 - 153

Full Terms \& Conditions of access and use can be found at http://hrmars.com/index.php/pages/detail/publication-ethics 


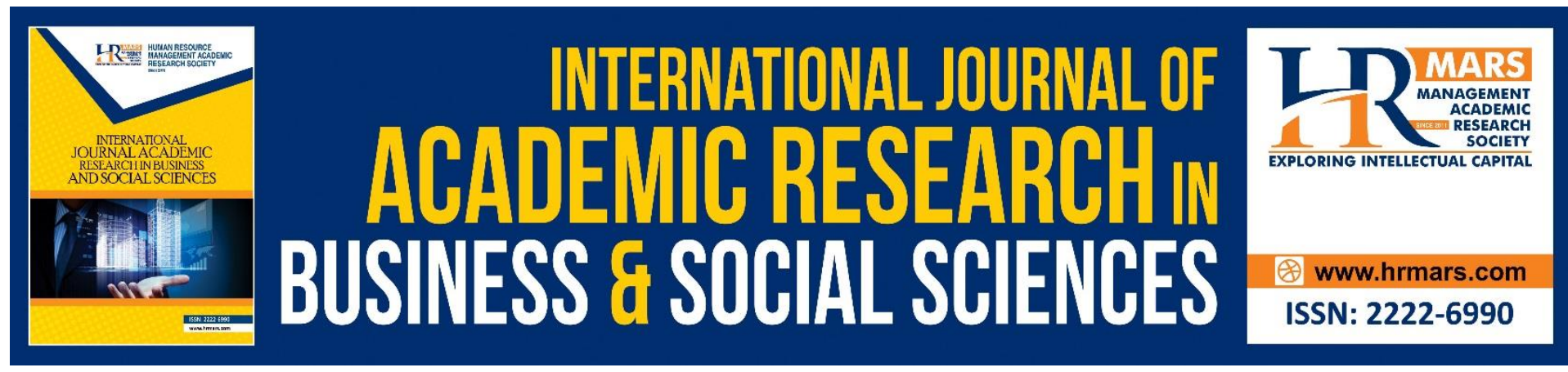

\title{
Survey Methods in Multinational, Multiregional, and Multicultural Contexts Book Review
}

\author{
Sokhi Huda, Clarissa Aisyah Putri \\ Sunan Ampel State Islamic University Surabaya, Indonesia. \\ Email: sokhi.huda@uinsby.ac.id, clarissaaputri@gmail.com
}

\begin{abstract}
The book Survey Methods in Multinational, Multiregional, and Multicultural Contexts (3M) was written by eight editors, reviewing the process of multi-sample, cross-country, and crosscultural surveys, based on 31 chapters in eight parts. Each part starts with the determination of a survey involving various countries. This book sees the smaller world from an academic point of view. The purpose of this book is to draw attention to important changes in the comparative method, identify research with new methods, and help indicate the need for researchers to identify linguistic and literary problems that have not been addressed before. Several ways, preparation, process, and research challenges are described in this book relate to the determination of questionnaires, adaptation of language, culture, even if there is no response or there are obstacles to state regulation. $3 \mathrm{M}$ research is the embryo of the concept of big data that developed into global research because of the internet of things. This book can be an appropriate guide for $3 \mathrm{M}$ survey research. Based on the substance of this book review, reviewers recommend four books as further reading, namely (1) Advances in Comparative Survey Methods: Multinational, Multiregional, and Multicultural Contexts (3MC), (2) Big Data Analysis and Deep Learning Applications: Proceeding of the First International Conference on Big Data Analysis and Deep Learning, (3) Global Journalism: Survey of International Communication, and (4) Global Journalism: A Survey of the World's Mass Media.
\end{abstract}

Keywords: Research Methods, Area Level, Area Coverage, Survey Area, Global Challenge

\section{Introduction}

The book "Survey Methods in Multinational, Multiregional, and Multicultural Contexts (3M)" was written by eight editors, reviewing the process of multi-sample, cross-country, and cross-cultural surveys. This book consists of 31 chapters which are divided into eight parts. Each part is presented from the determination of research or surveys involving various countries. This book sees that the world at the end can be seen as smaller from an academic perspective; people with the same problem in different countries gather to discuss and find solutions.

The purpose of this book, as outlined in the introduction, is to draw attention to important changes in the method of comparison, to identify research with new methods, and 
demonstrate the need for researchers to identify and recognize linguistically and literature that has not been handled before. At the beginning of the book, it was mentioned that multinational surveys and research projects are usually more complicated to do and more difficult to accept reliable results than surveys involving different cultural or ethnic populations in one country. Some of the difficulties outlined in this book relate to the determination of questionnaires, adaptation of language, culture, if there is no response to global survey programs or international surveys.

This book review is intended to take part in bringing the same mission of the writers or editors to continue creative and comprehensive thinking as a solution to the limitations of international surveys. This book is an appropriate guide to complete basic material for $3 \mathrm{M}$ (Multinational, Multiregional, and Multicultural) survey research.

\section{Pre-Survey 3M}

In the first part of this book (stage setting), editors try to manifest that a $3 \mathrm{M}$ survey is a form of research that is more complicated than other studies. Research involving intercultural cultures in the same country will not be as difficult as this research. In this chapter, consideration of this survey method is deliberately designed for comparative research that functions to develop and compare findings from two or more populations.

The first chapter does prepare its readers to go deeper and prove that 3M's research is complex but is needed even in the short 50 years. The editors explain:

In as much as international institutions and organizations-such as the European Commission, the Organization for Economic Co-operation and Development (OECD), the United Nations (UN), the United Nations Educational, Scientific and Cultural Organization (UNESCO), the World Bank, the International Monetary Fund (IMF), and the World Health Organization (WHO)-depend on multinational data to inform numerous activities, it has become ubiquitous and, in some senses, also commonplace (Harkness et al., 2010, p. 4).

This $3 \mathrm{M}$ research is useful for many international institutions and organizations. This research functions based on what multinational data is needed, what kind of goals, and what activities are desired. This research has a considerable influence everywhere.

In the first chapter, editors emphasized again, that this research is quite complicated and one of the things that makes it complicated is language. Although multinational surveys can be conducted in one language, most multi-population studies are also multilingual. Multinational here does not limit the language, for example some, countries with the same first language but different countries, this is still included in the multinational because there are cultural differences. Multiregional research can be in-country or cross-country research, and this term is used flexibly. This study groups countries into geographical groups such as north and south or intercontinental, as well as demographic features such as high or low births or deaths or populations. In this case, income variability is also included. Comparative surveys like this are conducted in different modes by comparing different populations in different countries. 


\section{M Survey}

\section{Questionnaire Format and Mode for the 3M Survey}

The design of the questionnaire for multi-population in this book sees that there are special designs that must be considered. The researcher aims to help the resource person or reader be able to understand the questionnaire as clearly as possible based on the information that has been developed in the questionnaire. The comparative instrument used in the $3 \mathrm{M}$ survey was specially designed for use with many populations. The instrument design must be appropriate and include contextual, conceptual aspects, selection of indicators, development of questions, levels, and vocabulary choices used. Furthermore, the important thing that must also be considered is the format or mode, the design of response categories, and technical features related to the problem discussed. One thing that is quite important to do in this multinational research is pretesting treatment with a smaller population. The consideration is that this research will involve many people with a considerable distance. Pretesting is quite useful for testing success points, although this strategy is not well received and tends to be underused.

Other things are quite an obstacle in the development of the questionnaire, namely language or translation, adaptation, data collection, documentation, harmonization, quality framework, and analysis. Constraints in several countries such as the United States, Egypt, Nepal, and others are also shown in this book. One method used to avoid difficulties in getting data, especially for areas that do not speak English, is a cognitive interview that uses the local language by involving people who can use two languages (bilingual). Examples given in this book are data collection in four non-English languages, namely Chinese, Korean, Russian, and Spanish, to make it easier for researchers to choose respondents who are young, highly educated, or if the data needs are not based on these criteria, then they will be the representative.

\section{Language as a Primary Challenge}

The third part of this book explains the obstacles one of which comes from translation. Verbal language does sometimes have brushy and different meanings in various countries, and translations that don't reach the bottom sometimes can't interpret the true intentions of those words. Linguistics here has a far more significant role than simply interpreting or translating but also interpreting meaning that is appropriate to the language and use of the word in his country. Even to improve this system, the authors also made a research design with a translation scale design and answers to avoid translation errors and find the most appropriate pattern or system to minimize the inaccuracy in translating a survey. The example given in the book is when a surveyor in China wrote "Do you eat other vegetables?" being wrong "How many times have you eaten other vegetables?" Different answers will affect the results of the survey.

The adaptations in this book relate to deliberate changes to meet material needs. Still related to translation, the development of materials as a form of adaptation can be done through many things, such as literary works, music, or film. In this case, adaptation is needed such as an instrument aimed at parents or children. 


\section{Looking for Answers through Cross-Country Culture and Habits}

As we know, in a country there may be more than two different cultures, let alone multinational or multiregional research. The $3 \mathrm{M}$ method, which has existed since the $1980 \mathrm{~s}$, paid attention to cultural differences. Communities have been described as diverse but are interdependent. In this book, the terms individualism and collectivism are embedded in countries that have a culture that is stuck together and similar to in ASIA or cultures that are quite striking in their differences like Spain and France, and so on.

In this chapter also, when researchers cognitively respond to cultural differences, they must be able to position themselves according to prevailing cultural customs. Thus, if the culture is much more difficult to get the results of the questionnaire answers, the researcher can make observations, then recall to rewrite the outline that has been captured and far more accurate if accompanied by evidence. There is something called honor-based research which should be fully supported by showing simplicity and closing insults. This is done if a researcher is in an area that still upholds culture.

\section{The Process of Reviewing Facts and Data}

An important component in this chapter is quality assurance and quality control of crossnational comparative studies. This is indeed quite confusing, but the intention is the need for quality assurance and quality control from the survey process to the results of the survey. This book cites Kish's writing in 1994, a cross-national comparative study aimed at distinguishing economic, social, cultural, and aspects of various countries or regions. Thus, the statistical problems that underlie linkages with cross-national studies are part of a larger field than the design and implementation of multi-population surveys.

Unfortunately, in cross-national comparative studies, there is a lack of depth in evaluating survey results. Two things that need to be evaluated are providing component estimates with biased results and / or providing recommendations for improvement. Next, this chapter provides examples of cross-cultural and cross-national research designs. Based on the description in this book, multinational and multicultural programs that are quite successful in using direct research in the community are the use of probability samples and procedures to select samples that are more representative. A coordinated focus on the design goals and target population for the entire survey. This will be taken into consideration in the crossnational and cross-cultural survey data collection phase.

The $3 \mathrm{M}$ survey always has special challenges, especially involving many countries. Because of the high costs, data collection must be a hindrance. Then the compilation of comparative literatures is needed to enrich and detail all phases of the survey cycle which greatly influences the survey results and process. These challenges can be difficult to achieve organizational structures, lack of response, and other mistakes. The process of aligning survey data to study social phenomena across time and countries is also needed. This serves to activate valid data and between the conclusions and the data presented are comparable.

\section{Why and What is Non-Response on 3M Survey?}

The use of respondent data is needed in understanding cross-national differences in nonresponse units. This is important for several reasons. Researchers need to know the response rate, and also need to know why the response rate can differ between countries. In particular, 
this can be a benchmark of the extent to which effectiveness and under what circumstances survey methods can achieve more effective results. The more contact data available, it will open up the possibility to be able to see non-responsive comparisons and find out the cause.

Non-response items and annual labor income data in panel surveys can be data and supplementary information. May be respondents did not response following the intent or purpose of the study. With complimentary data from various aspects, one of which is annual data, then conclusions can be drawn based on these supporting data. Non-response is different from total rejection. The purpose of non-response here is that the respondent cannot work in part because of the privacy and privacy or the unwillingness of the respondent or his inability to provide the information requested by the researcher. This behavior is called non-response items.

\section{Reading 3M Survey Data and Results}

Just like the results of a study's data analysis, the $3 \mathrm{M}$ survey also uses measurements and comparisons to find results and present them in a simpler form. In this book an explanation is given, that to show the results of several research techniques, the way to do this is to ignore the comprehensive thing and only focus on the results obtained and the main insights that have previously been agreed upon. Most of the analyzes presented based on this book provide some evidence that the results of the data cannot be compared to just one or two but all countries.

For data analysis, this type of survey uses a polytomous item response theory to examine items and test the differentiation of the data. In the results of the data, there may be errors and categorization differences in the quality of questions in the comparison survey. This can happen because of measurement errors or the quality of questions that can cause bias in research findings.

\section{M and Its Functions Globally}

Survey globalization may be developing rapidly. The more routine the state is and is free to conduct surveys, the national research volume is increasing. In this book it is explained that comparative studies make the world possible shrink, make it closer and underline the great challenges faced by survey research in general and survey research as a paradigm of total survey error. This last chapter discusses the development of cross-national surveys as general research with a focus on the evolution of the field of research surveys and major programs. Another global program used is the international social survey program, which is an annual cross-national social survey since 1985. Another program is Enhancing Quality and Comparability and the Comparative Study of Electoral Systems (CSES), then the latest is gallup as a world poll. The Gallup World Poll is usually used as the main survey which aims to measure the welfare conditions between countries and Gallup fully finances the Gallup World Poll as the largest multinational survey company ever conducted.

\section{Conclusions and Recommendations}

Without attachment to positive developments towards development to ensure accurate data, the challenges in multinational, multiregional, and multicultural survey research in this book are complete and technically and practically described. For academics who intend to engage in $3 \mathrm{M}$ research, this book can be used as a guide because not only is it non-technical 
about how 3M surveys deal with research challenges, but technically it can also be learned how to overcome them. This book can also be an appropriate guide for studying the results of research involving many countries such as Nielsen as a polling or survey agency and learning to translate the purpose of the research data presented.

This $3 \mathrm{M}$ research is the forerunner of the Big Data concept that has developed lately. If this book is read in general terms, it can be understood that so far, many policies, developing trends, and answers to global problems have been decided based on data and facts generated from the $3 \mathrm{M}$ survey. The embryo of $3 \mathrm{M}$ developed into a global study that is currently closed becaause of the technology or the internet of things. If this book seems unrelated to developments in the current era, maybe because this book has existed for one decade ago, as we know global developments and challenges will always grow and change. For this reason, the latest version of this book is the author's recommendation, namely; Advances in Comparative Survey Methods: Multinational, Multiregional, and Multicultural Contexts (3MC) (Johnson, Pennell, Stoop, \& Dorer, 2018).

The recommendation given by reviewers is that the $3 \mathrm{MC}$ book is a development work from the same publisher, namely John Wiley \& Sons, and several similar editors. This version, based on reviews made by Amazon Books, is an advanced form that is far more "advanced" than the previous series. This 2018 booklet presents a more detailed discussion of 3MC research. The development of this research has now become an important data bank that is not even needed by government, socio-politics, and economics but is more complex than that to security and privacy. This data bank is not even known to be voluntarily given. Furthermore, reviewers recommend the book Big Data Analysis and Deep Learning Applications: Proceeding of the First International Conference on Big Data Analysis and Deep Learning (Zin $\&$ Lin, 2018) for further reading. Specifically for the context of studies in Communication Science and Media, reviewers recommend two books, namely Global Journalism: Survey of International Communication (De Beer \& Merrill, 2004) and Global Journalism: A Survey of the World's Mass Media (Merrill, 1983). These last two books are closely related to big data as research material in the current era.

\section{Acknowledgment}

The authors of this article declare no conflict of interest. The authors are responsible for the content and writing of the paper.

\section{References}

De Beer, A. S., \& Merrill, J. (2004). Global Journalism: Survey of international communication. New York: Longman.

Harkness, J. A., Braun, M. E., Edwards, B. E., Johnson, T. P., Lyberg, L. E., Mohler, P. P., ... Smith, T. W. (Eds.). (2010). Survey methods in multinational, multiregional, and multicultural contexts. New Jersey: John Wiley \& Sons Inc.

Johnson, T. P., Pennell, B.-E., Stoop, I. A. L., \& Dorer, B. (Eds.). (2018). Advances in comparative survey methods: Multinational, multiregional, and multicultural contexts (3MC). New Jersey: John Wiley \& Sons.

Merrill, J. C. (1983). Global journalism: A survey of the world's mass media. New York: Longman Publishing Group.

Zin, T. T., \& Lin, J. C.-W. (2018). Big Data Analysis and Deep Learning Applications: Proceedings 
INTERNATIONAL JOURNAL OF ACADEMIC RESEARCH IN BUSINESS AND SOCIAL SCIENCES

Vol. 11, No. 3, 2021, E-ISSN: 2222-6990 @ 2021 HRMARS

of the First International Conference on Big Data Analysis and Deep Learning (Vol. 744, p. 386). Springer. 